\title{
Speech-Language Pathology Student Anxiety, Expectations, and Needs During Clinical Practicum
}

\author{
Laura W. Plexico \\ Auburn University, Iwp0002@auburn.edu \\ Allison M. Plumb \\ Auburn University, amp0016@auburn.edu \\ Daniel E. Phillips \\ dphill@uab.edu \\ DOI: doi.org/10.30707/TLCSD1.2Plexico
}

Follow this and additional works at: https://ir.library.illinoisstate.edu/tlcsd

Part of the Communication Sciences and Disorders Commons

\section{Recommended Citation \\ Plexico, Laura W.; Plumb, Allison M.; and Phillips, Daniel E. (2017) "Speech-Language Pathology Student Anxiety, Expectations, and Needs During Clinical Practicum," Teaching and Learning in Communication Sciences \& Disorders: Vol. 1: Iss. 2, Article 2. \\ DOI: doi.org/10.30707/TLCSD1.2Plexico \\ Available at: https://ir.library.illinoisstate.edu/tlcsd/vol1/iss2/2}

This Scholarship of Teaching and Learning Research is brought to you for free and open access by ISU ReD: Research and eData. It has been accepted for inclusion in Teaching and Learning in Communication Sciences \& Disorders by an authorized editor of ISU ReD: Research and eData. For more information, please contact ISUReD@ilstu.edu. 


\title{
Speech-Language Pathology Student Anxiety, Expectations, and Needs During Clinical Practicum
}

\begin{abstract}
The current study investigates clinical supervision with regard to millennial student clinician expectations, needs, and anxiety related to the supervisory process. Seven graduate students in speech-language pathology completed questionnaires at six points during their graduate education - The Student Clinician Anxiety Test (Sleight, 1985), as well as Larson's Supervisory Expectations Rating Scale and Supervisory Needs Rating Scale (Larson, 1981). Results indicated that supervisory needs and expectations were significantly greater pre-practicum when compared to post-externship, with no significant changes in student clinician anxiety noted across six semesters of graduate training. Student clinicians demonstrated less anxiety than Sleight's data, but had greater needs and expectations than Larson's data. The difference in anxiety may be a reflection of the cited confidence of millennials. The possibility also exists that supervisors have shifted their methods to incorporate recommended practices, promoting decreased anxiety. The higher level of expectation and needs is in keeping with the literature, which suggests that millennials live relatively structured lives and expect supervisors to provide structure and support to meet their learning needs.
\end{abstract}

\section{Keywords}

Student anxiety, student expectations, Practicum 


\section{Introduction}

Clinical practicum and the supervisory process is a major component of graduate programs for student clinicians training to become speech-language pathologists. The American Speech-Language Hearing Association (ASHA, 2008) position statement on clinical supervision in speech-language pathology indicates that "clinical supervision is a distinct area of practice in speech-language pathology and that it is an essential component in the education of student clinicians and the continual professional growth of speech-language pathologists" (para. 2). The supervisory process consists of a variety of activities and behaviors specific to the needs, competencies, and expectations of the supervisor and student clinician, in addition to the requirements of the practice setting. Despite the critical role of supervision in the graduate training process, there is limited empirical evidence that drives the supervisory process and best practice patterns for facilitating student clinician growth. In addition, of the information available, much focuses on previous generations of learners, specifically the baby boomers and Generation Xers. With millennial learners currently comprising a large student population within higher education, it is important to consider how their educational needs, including supervision, may differ from previous generations. Differences in learning styles may result in different expectations and needs of clinical supervisors, which need to be taken in to account when facilitating clinical education of graduate student clinicians.

\section{Generational Learning Styles}

Each generation of learners possesses a distinct set of characteristics that stems from shared experiences throughout their lifetimes. Members of these generations have similar values, beliefs, ideas, ethics, and learning styles that are distinctly different from those of the generations before and after them (See Table 1). Baby boomers, for example, are noted to display a great work ethic, are reported to be less technologically savvy, and prefer lecture based instruction. In contrast, members of Generation X are generally more comfortable with technology than their predecessors and strive for a balance between work and leisure (Johnson \& Romanello, 2005). Finally, millennials prefer collaborative learning and experiential activities, as well as immediate instructor feedback with low tolerance for delays (Billings \& Kowalski, 2004; Johnson \& Romanello, 2005; Oblinger, 2003). Millennial students are also accustomed to positive feedback and encouragement (Schofield \& Honore, 2009). With regard to characteristics that may negatively impact their education, millennials face a great deal of stress as they are the first generation since 1945 to face a more rigorous set of academic standards than any previous generation (Howe \& Strauss, 2000). 
Table 1. Generational Characteristics and Learning Styles

\begin{tabular}{|c|c|c|c|}
\hline Generation & Years & Characteristics & Learning Styles \\
\hline \multirow[t]{8}{*}{$\begin{array}{l}\text { Baby } \\
\text { Boomers }\end{array}$} & $1943-1960$ & Rebellious $^{\mathrm{a}}$ & Tactile $^{\mathrm{b}}$ \\
\hline & & Driven $^{\mathrm{a}}$ & Lecture-style $^{\mathrm{a}}$ \\
\hline & & Dedicated $^{\mathrm{a}}$ & Highly value grades ${ }^{\mathrm{a}}$ \\
\hline & & Punctual $^{\mathrm{a}}$ & $\begin{array}{l}\text { Desire course requirements } \\
\text { in advance }\end{array}$ \\
\hline & & Prepared $^{\mathrm{a}}$ & \\
\hline & & Motivated $^{\mathrm{a}}$ & \\
\hline & & Heightened work ethic ${ }^{a}$ & \\
\hline & & Struggle with technology ${ }^{\mathrm{a}}$ & \\
\hline \multirow[t]{7}{*}{$\begin{array}{l}\text { Generation } \\
\mathrm{X}\end{array}$} & 1961-1981 & Cynical $^{\mathrm{a}}$ & $\begin{array}{l}\text { Want exact course } \\
\text { requirements }\end{array}$ \\
\hline & & Clever $^{\mathrm{a}}$ & $\begin{array}{l}\text { Prefer straightforward } \\
\text { information }^{\mathrm{a}}\end{array}$ \\
\hline & & Resourceful $^{\mathrm{a}}$ & $\begin{array}{l}\text { Thrive when given } \\
\text { flexibility }^{\text {a }}\end{array}$ \\
\hline & & Tolerant $^{\mathrm{a}}$ & $\begin{array}{l}\text { Independent learning } \\
\text { environments }^{\mathrm{a}}\end{array}$ \\
\hline & & Comfortable with technologya & \\
\hline & & Balance work \& leisure ${ }^{a}$ & \\
\hline & & $\begin{array}{l}\text { Education leads to financial } \\
\text { stability }^{\mathrm{a}}\end{array}$ & \\
\hline \multirow[t]{9}{*}{ Millennials } & 1982-2002 & Optimistic $^{\mathrm{a}}$ & Collaborative $^{\mathrm{a}}$ \\
\hline & & Assertive $^{\mathrm{a}}$ & Experiential activities $^{\mathrm{a}}$ \\
\hline & & Friendly $^{\mathrm{a}}$ & $\begin{array}{l}\text { Immediate instructor } \\
\text { feedback }^{\mathrm{a}}\end{array}$ \\
\hline & & Respect authority $^{\mathrm{a}}$ & $\begin{array}{l}\text { Low tolerance for delayed } \\
\text { feedback }^{\mathrm{c}}\end{array}$ \\
\hline & & Diverse $^{a}$ & $\begin{array}{l}\text { Positive feedback and } \\
\text { encouragement }^{\mathrm{d}}\end{array}$ \\
\hline & & Connected $^{c}$ & Expect use of technology \\
\hline & & Technologically savvy ${ }^{a}$ & \\
\hline & & Skilled multi-taskers ${ }^{\mathrm{a}}$ & \\
\hline & & $\begin{array}{l}\text { Stressed to meet academic } \\
\text { standards }^{\mathrm{f}}\end{array}$ & \\
\hline
\end{tabular}

a Johnson \& Romanello (2005). ${ }^{\mathrm{b}}$ Cambiano, De Vore, \& Harvey (2001). ${ }^{\mathrm{c}}$ Oblinger (2003).

${ }^{\mathrm{d}}$ Schofield \& Honore (2009). ${ }^{\mathrm{e} B i l l i n g s ~ \& ~ K o w a l s k i ~(2004) . ~}{ }^{\mathrm{f}}$ Howe \& Strauss (2000). 
As generations evolve, so do the needs of the learners. Educators across disciplines, including the field of speech-language pathology, should consider the learning needs and preferences of their students and adjust learning opportunities within the classroom accordingly. The clinical training component of a degree in speechlanguage pathology adds another dimension. Clinical supervisors arguably need to account for both generational differences and the general anxieties and fears that student clinicians can experience during the supervisory process. For millennial learners, factors, such as the need for positive feedback, encouragement, and immediate instructor feedback, may result in increased supervisory needs and expectations. At the same time, the reported stress to meet academic standards may result in increased anxiety during the clinical supervision process.

\section{Anxiety during Clinical Education}

Irrespective of generational learning style, new experiences, situations, and responsibilities encountered can produce anxiety and fears when student clinicians begin their clinical education. In the correct amount, these feelings can be motivating and improve learning; however, too much fear or anxiety can have the opposite effect and impede the clinical learning process (Chan, Carter, \& McAllister, 1994; McCrea \& Brassuer, 2003). Student clinicians are anxious about many aspects of graduate school, and planning and conducting therapy is no exception. They enter the training process with significant role-related stress. More specifically, they are doubting their clinical knowledge and abilities (Bischoff, 1997; Skovholt \& Ronnestad, 1992) and experiencing stress over the ambiguity of their role (Capel, 1997). The source of anxiety and lack of self-confidence centers around meeting supervisor expectations, being responsible for the client, putting academic knowledge to clinical practice, and being able to conduct therapy (Chan, et al., 1994; McCrea \& Brassuer, 2003; Oratio, 1977; Sleight, 1985). Student clinicians often think they should know more than they do (Pickering \& McCready, 1990) and fear that asking for help will be perceived as a weakness or failure on their part. Bischoff (1997) reports that it is also not uncommon for student clinicians to feel as if they are masquerading as a clinician or as an imposter. The outcome of these feelings of anxiety or incompetence can include loss of sleep, the inability to concentrate, and physical symptoms such as dizziness or nausea.

Sleight (1985) studied clinician anxiety in speech-language pathology students. For this study, she developed The Sleight Clinician Anxiety Test (SCAT) to measure anxiety levels in four areas: (a) living up to the supervisory standards, (b) responsibility for clients, (c) transferring theory into practice, and (d) general feelings about practicum. Sleight reported that student anxiety levels increased prior to their first clinical practicum experience and decreased after this initial 
practicum experience. Findings also indicated that clinician anxiety did not continue to decrease with increased practicum experience. Students were reportedly most anxious about evaluations of their clinical performance and conferences held with clinical supervisors to discuss their evaluations.

Chan and colleagues (1994) also reported anxiety related to clinical education in 127 second, third, and fourth year undergraduate speech-language pathology students in Australia. Five causes of anxiety were common to all groups, including the ability to apply theory to practice, high expectations of self, amount of preparation for clinic, amount of relevant experience, and ability to fulfill both clinic and college demands. The source of anxiety was found to change as student clinicians progressed through their training. Beginning clinicians were anxious about report writing and their lack of clinical experience, whereas experienced clinicians, were more anxious about their relationship with the supervisor. That is, anxiety was present throughout the clinical education process; however, the cause of anxiety shifted as knowledge and experience increased.

\section{Reduction of anxiety in clinical education}

Recommendations to reduce student clinician anxiety have been cited in the literature and include the supervisor's recognition of the source of anxiety, the perception of how it changes over time, and an awareness that the source of anxiety will not be the same for all clinicians. Explaining and demystifying the supervisory process can help to alleviate student clinician anxiety (McCrea \& Brassuer, 2003; Perkins \& Mercaitis, 1995; Stengelhofen, 1993). The successful supervisor can reduce anxiety by promoting self-awareness, understanding the expectations associated with clinical objectives, maintaining a positive working relationship, and being cognizant of the supervisory needs of the student clinician. Further, knowing and sharing the expectations and goals for the clinical process is important for both the supervisor and the student clinician (McCrea \& Brasseur, 2003).

\section{Expectations and Needs of Student Clinicians}

Understanding the expectations and needs of student clinicians is an important aspect of effective clinical education and the supervisory process. A variety of adjectives, such as genuine, sensitive, knowledgeable, and flexible, have been used to describe the characteristics of a desirable and effective clinical supervisor. Other desirable characteristics reported by Pickering (1987) included the ability to be encouraging and facilitate independence by providing a safe, secure, and stimulating environment. Pickering further indicated that student clinicians believe that supervisors should function as a teacher, thereby bridging the gap between 
theory, principle, and application to the clinical process. Oratio, Sugarman, and Prass (1981) evaluated the factor structure or constructs associated with supervisory effectiveness. They found that factors associated with interpersonal interaction were the strongest predictor of perceived supervisor effectiveness and accounted for approximately $60 \%$ of the variance. They also found that factors related to being respectful and demonstrating empathy were the strongest indicators and predictive factors.

Dowling and Wittkopp (1982) also evaluated the supervisory needs of 191 undergraduate and graduate speech-language pathology students to determine a) whether perceived supervisory needs changed with clinical experience, b) whether supervisory needs were influenced by academic status, and c) what students perceived as desirable and undesirable supervisory behaviors. Their results demonstrated that students' supervisory needs were not influenced by academic status but changed as a function of perceived training. Beginning clinicians wanted more direct supervision with more frequent observations, while experienced clinicians wanted more collaboration and less frequent observation by the supervisor. Active problem solving, a collegial relationship with the supervisor, and increased accountability were all identified as desirable supervisory behaviors. At the end of a clinical training experience, Dowling (2001) reported that student clinicians expected the following supervisory behaviors: (a) be supportive, (b) enhance trainee's confidence, (c) provide honest feedback, (d) interact in a collegial way, (e) be helpful, (f) respond interpersonally in a sensitive way, (g) value the student clinician's independence, and (h) offer the student clinician praise. As student clinicians grow in clinical skills and independence, their expectations of the supervisor change, and this further indicates that the supervisor's style needs to change as the student clinicians develop their clinical skills.

Both student clinicians and their supervisors have their own expectations regarding the supervisory process. These expectations may include the level of supervision desired, the purpose of supervision, and the nature of communication in supervisory conferences (Larson, 1981). A student clinician's supervisory needs will influence interactions with their supervisor. While some student clinicians may feel that they need a great deal of supervision and guidance, others might feel that they should have more independence (Larson, 1981). To avoid conflict in supervisory interactions, "supervisors need to know about students' supervisory expectations and needs regarding roles, content, and nature of communication occurring during supervisory conferences" (Larson, 1981, p. 4). The Supervisory Expectations Rating Scale and Supervisory Needs Rating Scale can be used to help ensure effective supervisory interactions (Larson, 1981). 
Larson's Supervisory Expectations Rating Scale allows student clinicians to indicate what behaviors they expect of their clinical supervisors, and what supervisor behaviors they needed during supervisory conferences. Although the more inexperienced student clinicians had higher expectations and a greater need for supervisor involvement, Larson reported both inexperienced and experienced student clinicians having similar expectations about the supervisor's role in supervisory conferences. These expectations included asking questions, participating in conferences, having their ideas used and having their supervisors be supportive. With regard to needs, they wanted their points of view considered as well as assistance with developing treatment goals and intervention strategies.

\section{The Role of Self-Efficacy in the Anxiety, Expectation, and Needs of Student Clinicians}

The possibility also exists that anxiety, expectations, and needs change with degrees of self-confidence. In accordance with Bandura's (1982) social cognitive theory, self-efficacy, which is a reflection of self-confidence, influences performance by way of emotions (e.g., anxiety) and cognitions (e.g., expectations and needs). Bischoff and Barton (2002) conducted phone interviews with 39 graduate students who were in a marriage and family therapy program. Findings from the study indicate that the development of clinical self-confidence occurs over the course of three stages: variability in confidence, emerging confidence, and fragile stability in confidence. Stage one can last one to five months and is characterized by fluctuations in confidence that can be abrupt and dramatic in their shift. Students reported that confidence was situation dependent; and for that reason, they could feel very confident one moment and lack confidence the next. During this stage, they described anxiety as an indicator of confidence. The duration of stage two is five to six months, and the initial variability in confidence begins to lessen and become less situationally dependent. During this stage, therapists can begin to rely on previous clinical experience and begin to trust their own perceptions. Stage three is three to four months in duration, and self-confidence begins to stabilize. Clinicians begin to take ownership of the therapeutic and decision making processes. It is at this point that student clinicians begin to guide the therapy process.

\section{Purpose}

While the topic of clinician anxiety levels and supervisory expectations and needs have been investigated in the past, there is a dearth of recent evidence on the subject, particularly as it pertains to millennial learners. Given that most of the investigations related to this topic focused on the clinical training of students born 
in the baby boomer generation and Generation $\mathrm{X}$, it is of interest to know if these patterns and trends will continue with a new generation of student clinicians. Traits associated with millennial learners, such as a need for positive feedback, encouragement, and immediate instructor feedback may be reflected by an increase in supervisory needs and expectations of these students. Increased anxiety may be noted during the supervisory process as well, due to the high stress levels with regard to academic standards.

The purpose of the present pilot study is to investigate a) whether the level of anxiety in millennial students' changes during the course of graduate training and b) whether the current expectations and needs of millennial graduate student clinicians change over the course of graduate training. It was hypothesized that millennial student learners would have higher levels of anxiety at the outset of clinical practicum and have greater supervisory expectations and supervisory needs at the outset of their graduate training with significant differences between prepracticum and post externship experiences.

\section{Methodology}

Participants. Seven female student clinicians between the ages of 21 and $28(\mathrm{M}=$ 22.33; $\mathrm{SD}=2.24$ ) in a graduate speech-language pathology program volunteered to participate in this study. All of the student clinicians had completed the mandatory 25 hours of clinical observation and six had previous clinical experience which ranged from 2.5 hours to greater than 50 hours. While a range of clinical experience was noted, visual inspection revealed data that was normally distributed with no apparent outliers across each of the three measures (See Table 2).

Table 2. Participant Demographic Information

$\begin{array}{llll} & \text { Age } & \text { Sex } & \begin{array}{l}\text { Hours Clinical } \\ \text { Experience }\end{array} \\ \text { Participant 1 } & 28 & \text { F } & 0 \\ \text { Participant 2 } & 21 & \text { F } & 2.5 \\ \text { Participant 3 } & 22 & \text { F } & >50 \\ \text { Participant 4 } & 21 & \text { F } & 6 \\ \text { Participant 5 } & 21 & \text { F } & 24 \\ \text { Participant 6 } & 22 & \text { F } & 5.5 \\ \text { Participant 7 } & 21 & \text { F } & 4.5\end{array}$


Procedure. Three questionnaires were completed by each student clinician over the course of their graduate training program: the SCAT (Sleight, 1985), the Larson's Supervisory Expectations Rating Scale (Larson, 1981), and the Larson's Supervisory Needs Rating Scale (Larson, 1981). The scales were completed on six separate occasions. The scales were completed prior to a research interview that was conducted as part of a larger qualitative study investigating the graduate training experiences of speech-language pathologists. The first administration occurred prior to the start of the participants' graduate clinical practicum. Subsequently, student clinicians completed the scales after each semester of practicum (for a total of four semesters). The final administration of the scales took place following the student clinicians' final externship prior to graduation from the graduate program.

The Larson Supervisory Expectations Rating Scale (1981) measures student clinicians' expectations about their supervisors' behavior during future supervisory meetings, while the Larson Supervisory Needs Rating Scale (1981) indicates the extent to which student clinicians indicated a need these supervisor behaviors. Larson's Supervisory Expectations Rating Scale was derived from previous instruments designed to measure student clinicians' expectations for supervisory interactions (Larson, 1981). The scale is designed to reveal student clinician expectations for "supervisory conferences, verbal content, and nature of communicative interaction" (p. 47). The items on the Supervisory Expectations Rating Scale were modified to reflect needs as opposed to expectations on the Supervisory Needs Rating Scale. The Supervisory Expectations Rating Scale was determined by the author to possess both face and content validity through piloting and the use of comments made by pilot participants. Factor analysis was also conducted for the Supervisory Expectations and Needs scales to address construct validity. This analysis resulted in the construction of the two factors contained within each of the expectations and needs scales (i.e., supervisee focused and supervisor controlled), with alpha reliability coefficients greater than .60 .

Both Larson's Supervisory Expectations and Needs Scales consist of 26 items each. Using Likert-type scales, the student clinicians are asked to rate what they expect will happen during individual supervisory conferences (for Larson's Supervisory Expectations Scale) and what they need to occur at supervisory conferences, regardless of expectations (for Larson's Needs Scale), with 1 indicating a very little extent and 5 indicating a great extent. For the current investigation, 23 items were administered for each scale. The three qualitative, open-ended items were omitted because they are not included in the scale score. Based on the Likert-scale items, a maximum score of 115 could be obtained. 
The SCAT (Sleight, 1985) measures fear and anxiety levels across four categories: supervisor-clinician interaction, client well-being, application of theory to practice, and general attitudes toward practicum. For the SCAT, participants were asked to indicate degree of agreement with 40 statements using a 5-point Likert-type scale, where 1 is completely disagree and 5 is completely agree. The scores of all 40 statements were summed to yield a total SCAT score. Higher scores on the scale indicate greater anxiety, while lower scores on the scale indicate lower anxiety. Sleight (1985) determined that face and content validity were appropriate through reviews of supervisors and piloting instruments with graduate student clinicians. For the current study, split-half reliability for the SCAT was determined. The mean number of exactly consistent responses between paired items was $51 \%$, and the mean number of responses within one digit of exactly consistent responses was $85 \%$. Split-half reliability is considered acceptable.

\section{Results}

Using IBM SPSS Statistics 23, Friedman tests were conducted to evaluate differences in student clinician anxiety, supervisory expectations, and supervisory needs across six semesters of training and development. Table 3 lists the summary statistics for the three measures across the six semesters of training. Significance was set at $\alpha<0.05$. The Friedman test was significant for supervisory expectations across the six semesters, $\chi^{2}(5, \mathrm{~N}=7)=14.05, p=.015$. Follow up pairwise comparisons were conducted using the Wilcoxon signed-rank test and controlling for the Type I error across these comparisons at the .05 level using the LSD procedure. Median supervisor expectations were significantly greater during prepracticum when compared to all remaining semesters. Also, median supervisory expectations were significantly greater in their first semester when compared to post externship (see Table 4).

The Friedman test was also significant for supervisory needs across the six semesters, $\chi^{2}(5, N=7)=11.461, p=.043$. Using the Wilcoxon signed-rank test, pairwise comparisons were conducted. The LSD procedure was used to control for Type I error across these comparisons at the .05 level. Median supervisory needs were significantly greater during pre-practicum when compared to $4^{\text {th }}$ semester and post externship. Supervisory needs were also significantly greater during the first semester and second semesters as compared to the post externship (See Table 5). The Friedman test was not significant for changes in student clinician anxiety across the six semesters of graduate training, $\chi^{2}(5, \mathrm{~N}=7)=6.067, p=.300$. 
Table 3. Summary Statistics for the Sleight Clinician Anxiety Test, Supervisory Expectations, and Supervisory Needs

\begin{tabular}{lccccccccc}
\hline & \multicolumn{1}{c}{$\begin{array}{c}\text { Clinician } \\
\text { Anxiety }\end{array}$} & \multicolumn{4}{c}{$\begin{array}{c}\text { Supervisory } \\
\text { Expectations }\end{array}$} & \multicolumn{5}{c}{$\begin{array}{c}\text { Supervisory } \\
\text { Needs }\end{array}$} \\
\hline & $M$ & $\begin{array}{c}\text { Mean } \\
\text { Rank }\end{array}$ & $S D$ & $M$ & $\begin{array}{c}\text { Mean } \\
\text { Rank }\end{array}$ & SD & Mean & \\
& & & & & Rank & SD \\
\hline $\begin{array}{l}\text { Pre- } \\
\text { practicum }\end{array}$ & 120.57 & 4.57 & 4.58 & 94.14 & 5.64 & 5.18 & 87.43 & 4.93 & 5.91 \\
$\begin{array}{l}\text { Post } \\
\text { Semester 1 }\end{array}$ & 119.14 & 4.21 & 6.23 & 81.14 & 3.14 & 4.95 & 81.58 & 4.36 & 7.77 \\
$\begin{array}{l}\text { Post } \\
\text { Semester 2 }\end{array}$ & 117.14 & 3.57 & 4.71 & 84.57 & 3.64 & 7.16 & 79.86 & 3.50 & 5.96 \\
$\begin{array}{l}\text { Post } \\
\text { Semester 3 }\end{array}$ & 116.29 & 3.07 & 3.99 & 84.14 & 2.79 & 9.99 & 77.29 & 3.21 & 10.18 \\
$\begin{array}{l}\text { Post } \\
\text { Semester 4 }\end{array}$ & 114.57 & 2.57 & 4.54 & 83.71 & 3.57 & 12.53 & 74.71 & 3.14 & 12.97 \\
Post & 115.86 & 3.00 & 4.71 & 77.14 & 2.21 & 10.53 & 67.86 & 1.86 & 10.17 \\
Externship & & & & & & & & & \\
\hline
\end{tabular}

Note. $M=$ mean; $S D=$ standard deviation

Table 4. $p$ Values for Pairwise Comparisons between Semesters for Supervisory Expectations

\begin{tabular}{lllllll}
\hline & Semester & Semester & Semester & Semester & Semester & Semester \\
& 1 & 2 & 3 & 4 & 5 & 6 \\
\hline $\begin{array}{l}\text { Pre- } \\
\text { Practicum }\end{array}$ & - & $.027^{*}$ & $.018^{*}$ & $.018^{*}$ & $.028^{*}$ & $.028^{*}$ \\
$\begin{array}{l}\text { Post Semester } \\
1\end{array}$ & - & - & .173 & .866 & .398 & $.018^{*}$ \\
$\begin{array}{l}\text { Post Semester } \\
2\end{array}$ & - & - & - & .236 & .735 & .116 \\
$\begin{array}{l}\text { Post Semester } \\
3\end{array}$ & - & - & - & - & .397 & .207 \\
$\begin{array}{l}\text { Post Semester } \\
4\end{array}$ & - & - & - & - & - & .128 \\
Post & - & - & - & - & - & - \\
Externship & & - & & & & \\
\hline
\end{tabular}

Note. Asterisks indicate statistical significance 
Table 5. $p$ Values for Pairwise Comparisons between Semesters for Supervisory Needs

\begin{tabular}{|c|c|c|c|c|c|c|}
\hline & $\begin{array}{l}\text { Semester } \\
1\end{array}$ & $\begin{array}{l}\text { Semester } \\
2\end{array}$ & $\begin{array}{l}\text { Semester } \\
3\end{array}$ & $\begin{array}{l}\text { Semester } \\
4\end{array}$ & $\begin{array}{l}\text { Semester } \\
5\end{array}$ & $\begin{array}{l}\text { Semester } \\
6\end{array}$ \\
\hline $\begin{array}{l}\text { Pre- } \\
\text { Practicum }\end{array}$ & - & .271 & .128 & $.046^{*}$ & .063 & $.028^{*}$ \\
\hline $\begin{array}{l}\text { Post } \\
\text { Semester } 1\end{array}$ & - & - & .462 & .352 & .128 & $.018^{*}$ \\
\hline $\begin{array}{l}\text { Post } \\
\text { Semester } 2\end{array}$ & - & - & - & .670 & .612 & $.043^{*}$ \\
\hline $\begin{array}{l}\text { Post } \\
\text { Semester } 3\end{array}$ & - & - & - & - & .553 & .090 \\
\hline $\begin{array}{l}\text { Post } \\
\text { Semester } 4\end{array}$ & - & - & - & - & - & .236 \\
\hline $\begin{array}{l}\text { Post } \\
\text { Externship }\end{array}$ & - & - & - & - & - & - \\
\hline
\end{tabular}

Note. Asterisks indicate statistical significance

\section{Discussion}

Although significance was not found for clinician anxiety, mean student clinician anxiety was found to decrease as the student clinicians progressed through the graduate training program. This indicates that the student clinicians became less anxious and more confident with increased experience. This outcome is similar to previous research that found overall reductions in student clinician anxiety as students progressed through their training (Chan, et al., 1994; Sleight, 1985). Though, it should be noted that individual variability was observed, and student clinician anxiety was not observed to systematically decrease for each student each semester. As student clinician anxiety has been documented to occur throughout the clinical education process and can impact clinical learning (Chan et al., 1994; McCrea \& Brassuer, 2003), this topic merits much consideration by clinical supervisors. Student clinician anxiety can be reduced by supervisors recognizing the source of anxiety, developing an awareness that all clinicians will not be anxious about the same areas, and explaining and/or demystifying the supervisory process (McCrea \& Brassuer, 2003). Student clinicians often experienced a slight shift upwards before they had an off-campus placement, which is understandable in light of the impending need to adjust to a new clinical site with new paperwork requirements, clinical procedures, client populations, billing practices, etc.

In comparison to Sleight's (1985) data, the seven participants in the current study had lower anxiety scores throughout the graduate experience than Sleight's 44 baby boomers. The lowered anxiety scores may be a reflection of the cited confidence of 
the millennial generation (Elam, Stratton, \& Gibson, 2007; Howe, 2005). The possibility also exists that supervisors have shifted their supervisory methods since Sleight's data, and fall in line with recommended practices (e.g., explanation of the supervisory process to the student clinician, promotion of self-awareness) as the literature base on millennials grows in the field of supervision (McCrea \& Brassuer, 2003; Perkins \& Mercaitis, 1995; Stengelhofen, 1993) which promotes decreased anxiety in the student clinician.

Over the duration of the program, both clinician expectations and needs decreased throughout graduate training with the most notable decrease in scores occurring from pre-clinic to post-first semester. In general, student clinician expectations were found to be greater than student clinician needs. Although overall scores decreased, the study of individual participant responses on both scales indicates that there is variability among participants between and across semesters. In comparison to Larson's (1981) data, the participants in the current investigation needed more and had greater expectations than Larson's 95 baby boomers. This finding aligns with the literature, which suggests that millennials have lived relatively structured lives and expect supervisors to provide structure and support to meet their learning needs (Borges, Manuel, Elam, \& Jones, 2006; Wilson, 2004). The millennials made greater changes over time which yields a larger overall score change in expectations and needs. The millennial learners were also found to have slightly fewer needs and expectations than Larson's baby boomer experienced clinicians post externship, which may also relate to the cited confidence of the millennial generation.

\section{Clinical Implications}

While generational similarities were evident in the results of this investigation, it is recommended that clinical educators consider and determine the specific needs and expectations of each student clinician at the beginning of the semester. Furthermore, the expectations of clinical educators often increase as clinicians progress in graduate training and may influence the student clinician's needs and/or expectations. Off campus supervisors should also be aware of changes that occur from semester-to-semester and should not assume that student clinicians will have an increase or decrease in needs or expectations. Training experience and supervision should match the developmental needs and expectations of the student clinicians. Often, when a student clinician goes off campus for the first time, they will be working with a population that they have had very little experience with or exposure to, which can then result in greater anxiety levels, expectations, and needs.

As stated in the literature review, the possibility exists that anxiety, expectations and needs change with degrees of self-confidence. Self-efficacy (Bandura, 1982), 
a reflection of self-confidence, influences performance by way of emotions (e.g., anxiety) and cognitions (e.g., expectations and needs). In the context of graduate training, student self-confidence can be defined as the degree of certainty a student has with regard to their clinical performance abilities. Bischoff and Barton's (2002) study indicated that during stage one, when anxiety is described as an indicator of confidence, supervisors should focus on what clinicians are doing well by highlighting specific in-session behaviors and what is conceptually positive about those behaviors within the overall therapeutic approach. During stage two, when therapists can trust previous clinical experience and begin to trust their own perceptions, supervision should encourage clinicians to make more session-bysession decisions and create a therapeutic environment where the clinician can see their own success. During stage three, when clinicians begin to take ownership of the therapeutic process, supervisors should allow student clinicians to guide the supervision process.

For supervisors to meet the needs and expectations of graduate speech-language pathology student clinicians and to alleviate stress that can result in student clinician anxiety, it is important for educators to realize that they must consider the student clinician's perception and how it can impact the quality of their clinical education. Clinical education is a foundational and necessary part of graduate training that teaches speech-language pathology student clinicians what they need to know to be competent professionals. With that comes personal feelings of stress and anxiety, as well as significant expectations and needs of supervisors. Carlson, Kotze, and Van Rooyen (2005) suggested that the anxiety associated with the training process can be alleviated with proper support and counseling. Future research needs to focus on how supervisors and clinical educators of the millennial learners can alleviate unnecessary stress and create an atmosphere where the expectations and needs of the millennial learner and supervisor are congruent.

\section{Limitations and Future Research Directions}

While many data points were collected over time in the current investigation, a study with a larger number of student clinicians from more varied geographical backgrounds and different university settings may be more generalizable. Comparisons to the previous work of Larson (1981) and Sleight (1985), while of interest, should also be interpreted with caution due to the difference in sample sizes. As suggested in the discussion, the possibility exists that supervisors are following recommended practice patterns to reduce anxiety associated with the supervisory process. It may be of interest to find out the degree to which this is occurring. A survey of clinical supervisors to determine their current supervision philosophies and procedures would be of interest. Finally, further qualitative 
investigation could examine data pertaining to student clinician's experiences throughout the supervisory process. Interviews of graduate clinicians could be evaluated and could provide information on the perceptions of clinical supervision, as well as the anxiety and strengths/needs of student clinicians associated with the supervisory process.

\section{Conclusion}

The student clinicians' supervisory expectations and needs scores were found to significantly differ across the six semesters, with a decrease observed throughout graduate training. Significance was not found for clinician anxiety. Pairwise comparisons revealed that reductions in supervisory needs and supervisory expectations were observed by the end of their sixth semester. When descriptive statistics are compared to previous work, generational differences were observed. Specifically, the current sample of millennial learners was observed to have greater supervisor expectations and needs, but less clinician anxiety. These findings could reflect the increased confidence of the millennial learner as well as the desire for increased structure and support associated with this generation.

\section{References}

American Speech-Language-Hearing Association. (2008). Clinical supervision in speech-language pathology [Position Statement]. Retrieved from www.asha.org/policy.

Bandura, A. (1982). Self-efficacy mechanism in human agency. American Psychologist, 37(2), 122-147.

Bischoff, R. J. \& Barton, M. (2002). The pathway toward clinical self-confidence. The American Journal of Family Therapy, 30(3), 231-242.

Bischoff, R. J. (1997). Themes in therapist development during the three months of clinical experience. Contemporary Family Therapy, 19, 563-580.

Billings, D. \& Kowalski, K. (2004). Teaching learners from varied generations. The Journal of Continuing Education in Nursing, 35(3), 104-105.

Borges, N.J., Manuel, R.S., Elam, C.L., \& Jones, B.J. (2006). Comparing Millennial and Generation $\mathrm{X}$ medical students at one medical school. Academic Medicine, 81(6), 571-576.

Cambiano, R. L., De Vore, J. B., \& Harvey, R. L. (2001). Learning style preferences of the cohorts: Generation x, Baby Boomers, and the silent generation. PAACE Journal of Lifelong Learning, I10, 31-39.

Capel, S. A. (1997). Changes in students' anxieties and concerns after their first and second teaching practices. Educational Research, 39(2), 211-228. 
Carlson, S., Kotze, W. J., \& Van Rooyen, D. (2005). Accompaniment needs of first year nursing students in the clinical learning environment. Curationis, 4, 30-39.

Chan, J., Carter, S., \& McAllister, L. (1994). Sources of anxiety related to clinical education in undergraduate speech-language pathology students. Australian Journal of Human Communication Disorders, 22, 57-73.

Dowling, S. (2001). Supervision: Strategies for successful outcomes and productivity. Needham Heights, MA: Allyn and Bacon.

Dowling, S., \& Wittkopp, J. (1982). Students' perceived supervisory needs. Journal of Communication Disorders, 15, 319-328.

Elam, C., Stratton, T., \& Gibson, D.D. (2007). Welcoming a new generation to college: the millennial students. Journal of College Admissions, 195, 20-25.

Howe, N. (2005). Harnessing the power of Millennials. School Administrator, 62(8), 18-22.

Howe, N.\& Strauss, W. (2000). Millennials rising: the next great generation. New York, NY: Vintage Books.

Johnson, S. A. \& Romanello, M. L. (2005). Generational diversity: Teaching and learning approaches. Nurse Educator, 30(5), 212-216.

Larson, L. C. (1981). Perceived supervisory needs and expectations of experienced vs. inexperienced student clinicians. PhD diss., Indiana University.

McCrea, E. S. \& Brasseur, J. A. (2003). The supervisory process in speechlanguage pathology and audiology. Boston: Allyn and Bacon.

Oblinger, D. (2003). Boomers, gen-xers, and Millennials: Understanding the new students. Educause, 38(4), 37-47.

Oratio, A. R. (1977). Supervision in Speech-Language Pathology: A Handbookfor Supervisors and Clinicians. Baltimore, MD: University Park Press.

Oratio, A., Sugarman, M., and Prass, M. (1981). A multivariate analysis of clinicians' perceptions of supervisory effectiveness. Journal of Communication Disorders, 14, 31-42.

Perkins, J. M. and Mercaitis, P. A. (1995). A guide for supervisors and students in clinical practicum. The Clinical Supervisor, 13, 67-79.

Pickering, M. (1987). Supervision: A person focused process. In M. Crago \& M. Pickering (Eds.), Supervision in human communication disorders: Perspectives on a Process (pp.107-133). Boston: College-Hill.

Pickering, M., \& McCready, V. (1990). Interpersonal communication skills: A process in action. In ASHA (Ed.), Proceedings of 1989 ASHA Educational Program: Clinical Supervision Across Settings: Communication and Collaboration. Rockville, MD: ASHA.

Schofield, C. P. \& Honore, S. (2009). Generation Y and learning. The Ashridge Journal, Winter, 26-32. 
Skovholt, T. M. \& Ronnestad, M. N. (1992). Themes in therapist and counselor development. Journal of Counseling and Development, 70, 505-515.

Sleight, C. (1985). Confidence and anxiety in student clinicians. The Clinical Supervisor, 3, 25-48.

Stengelhofen, J. (1993). Teaching students in clinical settings. London: Chapman \& Hall

Wilson, M. E. (2004). Teaching, learning, and millennial students. New Directions for Student Services, 106, 59-71. 